\title{
Malignant transformation of oral leukoplakia: a retrospective cohort study of 218 Chinese patients
}

\author{
Wei Liư ${ }^{\dagger}$ Yu-Feng Wang ${ }^{\dagger}$, Hai-Wei Zhou, Peng Shi, Zeng-Tong Zhou*, Guo-Yao Tang ${ }^{*}$
}

\begin{abstract}
Background: Oral leukoplakia $(\mathrm{OL})$ is the best-known potentially malignant disorder. A new binary system to grade dysplasia was proposed by $\mathrm{WHO}$, but the biological significance in predicting malignant transformation risk is unknown. The objective of this study is to estimate the rate of malignant transformation in a long-term follow-up cohort, explore the usefulness of the new binary system of grading dysplasia and identify significant risk factors of OL malignant transformation in China.
\end{abstract}

Methods: A total of 218 patients with clinical and histopathologic diagnosis of OL were retrospectively reviewed. They were selected among all archived files at the Department of Oral Mucosal Diseases, Ninth People's Hospital, Shanghai Jiao Tong University School of Medicine. The mean follow-up period was 5.3 years.

Results: Among 218 cases, 39 (17.9\%) OL patients developed oral cancer, with a mean duration of 5.2 years. Cox regression analysis revealed that dysplasia was an independent risk factor for OL malignant transformation, but age, gender, lesion site, diet habit, smoking and ethanol intake were not risk factors. High-risk dysplastic OL was associated with a 4.57-fold (95\% confidence interval, 2.36-8.84; $\mathrm{P}<0.001$ ) increased risk of malignant transformation, compared with low-risk dysplasia. Consistent with this result, high-risk dysplastic OL had signicantly higher malignant incidence than low-risk dysplasia, particularly during the first 2-3 years of follow-up, by KaplanMeier analysis (Log-rank test, $P<0.001$ ).

Conclusions: The new binary system's function in predicting OL malignant transformation risk was investigated in this survey. The utilization of high-risk dysplasia as a significant indicator for evaluating malignant transformation risk in patients with OL was suggested, which may be helpful to guide treatment selection in clinical practice.

\section{Background}

Oral squamous cell carcinoma (OSCC) is widely recognized as the most common type of head and neck cancer, with a $\sim 50 \%$ survival rate over 5 years despite various treatments in the past three decades $[1,2]$. Oral leukoplakia (OL) is defined as "A white plaque of questionable risk having excluded (other) known diseases or disorders that carry no increased risk for cancer", which is the best-known potentially malignant disorder of the oral mucosa $[3,4]$. Reports indicate that $15.8-48.0 \%$ of OSCC patients were associated with OL when

\footnotetext{
* Correspondence: liuweb@hotmail.com; tanggy@shsmu.edu.cn

† Contributed equally

Department of Oral Mucosal Diseases, Ninth People's Hospital, Shanghai Jiao

Tong University School of Medicine, Shanghai Key Laboratory of

Stomatology, China. No. 639 Zhizaoju Road, Shanghai 200011, China
}

diagnosed [5-8]. Pooled estimate of annual rate of OL malignant transformation is $1.36 \%$ (95\% confidence interval, $0.69 \%-2.03 \%$ ) in various populations and geographical areas [9]. Possibly due to the rarity of cohort studies in developing nations, a concrete conclusion on the global annual rate of OL transformation is not currently available [10].

Histopathologically, oral epithelial dysplasia currently is the most important prognostic indicator for determining the malignant transformation risk of OL [11]. Traditionally, OL lesions are classified as non-dysplasia (hyperplasia) and dysplasia (mild, moderate or severe). At a workshop coordinated by the WHO Collaborating Centre for Oral Cancer and Precancer in the United Kingdom on issues related to oral potentially malignant disorders, a binary classification (no/ 
questionable/mild-low risk; moderate/severe-high risk) of the lesion was recommended. The move was intended to reduce the subjectivity inherent in grading dysplasia, which may increase the likelihood of agreement between pathologists [12]. Kujan et al. recently tested the new binary system of grading oral dysplasia and supported this view [13]. However, the biological significance of this grading system needs to be researched in longitudinal studies to explore its relevance in predicting malignant transformation risk of epithelial precursor lesions [12].

The risk factors of clinical features and lifestyle habits associated with transformation of OL into carcinoma have been evaluated in previous studies. Napier and Speight recently reviewed clinical predictors of malignant transformation in oral leukoplakia, such as age, gender and lesion site, but the results from different study populations vary [10]. The role of smoking and ethanol intake as important risk factors related to malignant transformation remains controversial and unclear [14-16]. Thus, assessment of these factors for OL malignant transformation is still needed.

The objective of the present study is to estimate the malignant transformation rate of a retrospective cohort of 218 patients with OL (mean follow-up of 5.3 years), explore the usefulness of the new binary system of grading dysplasia and identify significant risk factors of OL malignant transformation in China.

\section{Methods}

\section{Study population}

All archived files of patients with the clinical and pathologic diagnosis of OL from 1978 to 2008 were retrospectively reviewed in the Department of Oral Mucosal Diseases, Ninth People's Hospital, Shanghai Jiao Tong University School of Medicine. All clinical history and follow-up data were obtained from the archived files. Information regarding gender, age, site of lesions at the time of the initial diagnosis of OL was all documented in detail. Diet habit, history of smoking and ethanol intake were also collated through the files. According to the definition of OL, "A white plaque of questionable risk having excluded (other) known diseases or disorders that carry no increased risk for cancer", the exclusion criteria were as follows:

I. Any patient without the initial histopathologic examination of OL and development of OSCC during a follow-up period by biopsy or surgery.

II. Any patient with the clinical history and histopathologic changes of oral white or predominantly white oral benign diseases, for example, linea alba, leukoedema, leukokeratosis; and oral precancerous conditions such as discoid lupus erythematosus and lichen planus.
III. Any patient with diagnosis of OL concomitant OSCC at the first visit.

IV. Any patient with a follow-up period of less than 12 months.

Based on these criteria, 218 patients with OL were selected to be retrospectively reviewed in the cohort. This study was approved by the institutional review board of Ninth People's Hospital, Shanghai Jiao Tong University School of Medicine.

\section{Histopathologic examination}

The histopathologic diagnosis of all cases was determined by an oral pathologist on duty from the Department of Oral Pathology, Ninth People'sHospital, Shanghai Jiao Tong University School of Medicine. The confirmation diagnosis and reclassification was performed by another oral pathologist (J. L.). The WHO criteria for OL were used when examining the histopathology of the sections [17]. According to the binary grading system newly proposed by WHO [12], reexamination of the sample confirmed the diagnosis of epithelial dysplasia. The architecture (a total of 7 scoring) and cytology (a total of 9 scoring) criteria for epithelial dysplasia were as follows:

Architecture: 1) Irregular epithelial stratification; 2) Loss of polarity of basal cells; 3 ) Drop-shaped rete ridges; 4) Increased number of mitotic figures; 5) Abnormally superficial mitoses; 6) Premature keratinization in single cells; 7) Keratin pearls within rete ridges.

Cytology: 1) Abnormal variation in nuclear size; 2) Abnormal variation in nuclear shape; 3) Abnormal variation in cell size; 4) Abnormal variation in cell shape; 5) Increased nuclear-cytoplasmic ratio; 6) Increased nuclear size; 7) Atypical mitotic figures; 8) Increased number and size of nucleoli; 9) Hyperchromasia.

We reclassified all lesions as low-risk dysplasia and high-risk dysplasia in the present study. A low-risk lesion was based on observing less than four architectural changes or less than five cytological changes. A high-risk lesion was based on observing at least four architectural changes and five cytological changes.

\section{Statistical analysis}

A descriptive analysis was performed on clinical and pathologic factors. The $\chi^{2}$ test and Fisher exact test were employed to assess the association among categorical variables. For time-to-event analysis, Kaplan-Meier curves were plotted and log-rank test was used. Cox proportional hazards models were utilized for 
clinicopathological factors in prediction of malignant transformation risk. Hazard ratios (HR) with 95\% confidence interval $(95 \% \mathrm{CI})$ and $\mathrm{P}$ values were reported. All tests were two-sided, and $\mathrm{P}$ values $<0.05$ were considered statistically significant.

\section{Results}

\section{Patient Characteristics}

A total of 218 patients were enrolled in this retrospective study, with a mean follow-up period of 5.3 years. Of these, 39 (17.9\%) patients developed invasive oral cancer, with the mean time of malignant transformation of 5.2 years.

The baseline characteristics of OL are presented in Table 1. For all the subjects, the gender ratio was equal (110 males: 108 females). The average age at diagnosis

\section{Table 1 Baseline characteristics of oral leukoplakia}

\begin{tabular}{|c|c|}
\hline Characteristic & $\begin{array}{l}\text { Patients } \\
\text { n (\%) }\end{array}$ \\
\hline Total & 218 \\
\hline \multicolumn{2}{|l|}{ Age, y } \\
\hline Mean (SD) & $52.7(11.2)$ \\
\hline Range & $21-84$ \\
\hline$<40$ & $24(11.0)$ \\
\hline $40-49$ & $59(27.1)$ \\
\hline $50-59$ & $72(33.0)$ \\
\hline$>=60$ & $63(28.9)$ \\
\hline \multicolumn{2}{|l|}{ Gender } \\
\hline Female & 108 (49.5) \\
\hline Male & $110(50.5)$ \\
\hline \multicolumn{2}{|l|}{ Site } \\
\hline Tongue & $112(51.4)$ \\
\hline Buccal mucosa & 71 (32.6) \\
\hline Gingiva & $14(6.5)$ \\
\hline Palate & $13(6.0)$ \\
\hline Floor of mouth & $7(3.2)$ \\
\hline Lip & $1(0.5)$ \\
\hline \multicolumn{2}{|l|}{ Diet habit } \\
\hline Bland & 177 (81.2) \\
\hline Spicy & $28(12.8)$ \\
\hline Missing & $13(6.0)$ \\
\hline \multicolumn{2}{|l|}{ Smoking } \\
\hline Never & $145(66.5)$ \\
\hline Past and present & $65(29.8)$ \\
\hline Missing & $8(3.7)$ \\
\hline \multicolumn{2}{|l|}{ Ethanol intake } \\
\hline Never & $193(88.5)$ \\
\hline Past and present & $15(6.9)$ \\
\hline Missing & $10(4.6)$ \\
\hline \multicolumn{2}{|l|}{ Epithelial dysplasia } \\
\hline Low-risk & 180 (82.6) \\
\hline High-risk & 38 (17.4) \\
\hline
\end{tabular}

was 52.7 years old (range 21-84). The peak incidence was fifth decade of life (33.0\%). Tongue was affected in $51.4 \%$ patients with OL, followed by buccal mucosa (32.6\%). Few lesions were located on the floor of mouth and lip. There were $12.8 \%$ patients with spicy dietary habit. The history of smoking and ethanol intake were observed in $29.8 \%$ and $6.9 \%$ cases, respectively. We found $180(82.6 \%)$ OL cases were low-risk dysplastic lesions and 38 (17.4\%) OL cases were high-risk dysplastic lesions. Table 2 illustrates the association between OL and clinical parameters. Differences in age, gender, lesion site, diet habit, smoking, and ethanol intake were not observed between the untransformed and transformed OL.

Oral cancer-free survival (OCFS) analysis of risk factors To investigate the time to malignant event of OL, we performed the Kaplan-Meier analysis for cancer-free survival by clinicopathological parameters. Dysplasia and lesion site were significant parameters by Log-rank test (Figure 1). Among 218 OL lesions, 23 of 180 low-risk dysplasia and 16 of 38 high-risk dysplasia developed into cancer, respectively. We observed that a high-risk dysplastic OL was associated with an increased oral cancer risk, particularly during the first 2-3 years of the followup (Log-rank test, $\mathrm{P}<0.001$; Figure $1 \mathrm{~A})$. The 5-year

Table 2 Characteristics of untransformed (UT) and malignant transformed (MT) oral leukoplakia

\begin{tabular}{|c|c|c|c|}
\hline \multirow{3}{*}{ Characteristic } & \multicolumn{2}{|c|}{ Oral leukoplakia, n (\%) } & \multirow{3}{*}{ P-value } \\
\hline & UT & MT & \\
\hline & $n=179$ & $n=39$ & \\
\hline Age, y & & & 0.846 \\
\hline$<60$ & $128(71.5)$ & $27(69.2)$ & \\
\hline$>=60$ & $51(28.5)$ & $12(30.8)$ & \\
\hline Gender & & & 0.113 \\
\hline Female & $84(46.9)$ & $24(61.5)$ & \\
\hline Male & $95(53.1)$ & $15(38.5)$ & \\
\hline Site & & & 0.051 \\
\hline Tongue & $86(48.0)$ & $26(66.7)$ & \\
\hline Others sites & $93(52.0)$ & $13(33.3)$ & \\
\hline Diet habit & & & 0.179 \\
\hline Bland & $143(84.6)$ & $34(94.4)$ & \\
\hline Spicy & $26(15.4)$ & $2(5.6)$ & \\
\hline Missing & $10(-)$ & $3(-)$ & \\
\hline Smoking & & & 0.176 \\
\hline Never & $115(66.9)$ & $30(78.9)$ & \\
\hline Past and present & $57(33.1)$ & $8(21.1)$ & \\
\hline Missing & $7(-)$ & $1(-)$ & \\
\hline Ethanol intake & & & 0.484 \\
\hline Never & $159(93.5)$ & $34(89.5)$ & \\
\hline Past and present & $11(6.5)$ & $4(10.5)$ & \\
\hline Missing & $9(-)$ & $1(-)$ & \\
\hline
\end{tabular}



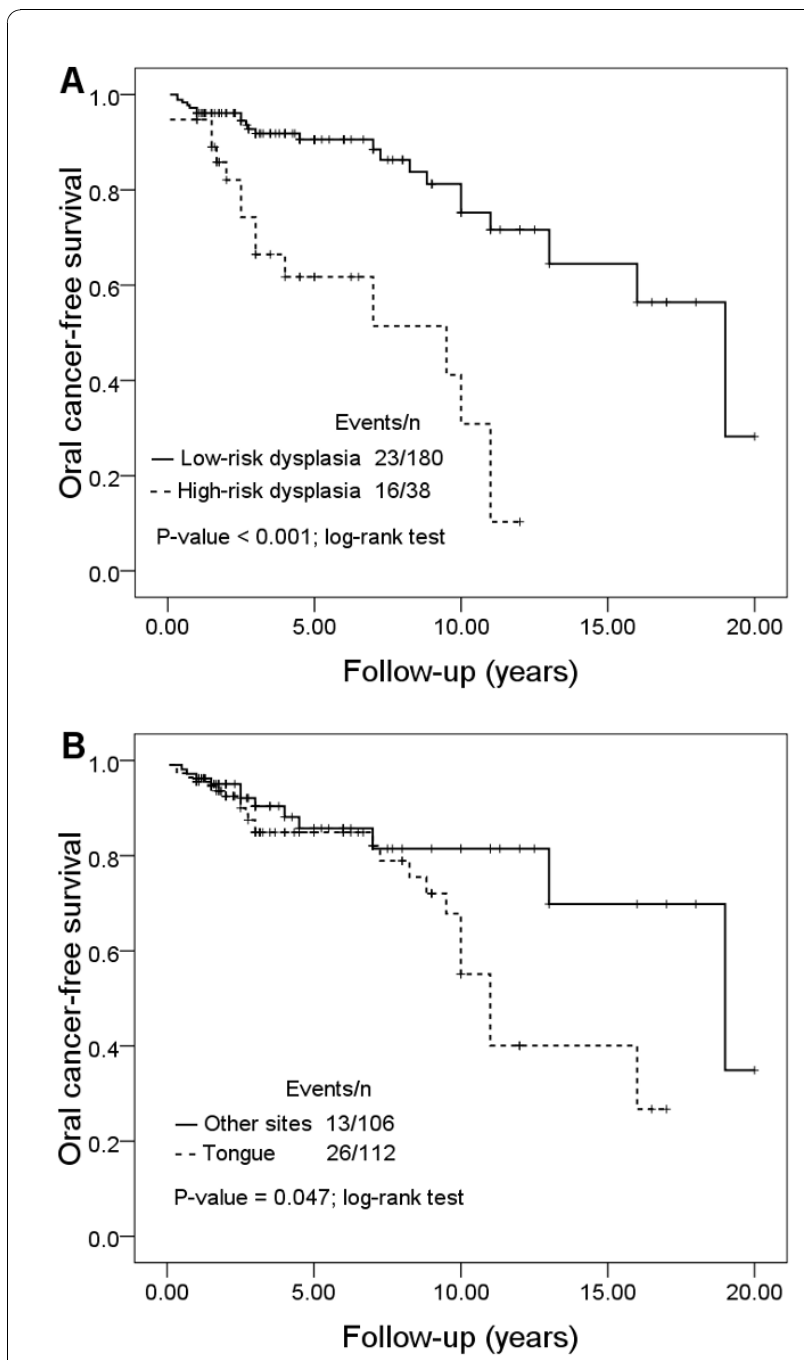

Figure 1 Oral cancer-free survivals (OCFS). (A) by low-risk and high-risk dysplasia. (B) by tongue and other sites of lesion.

OCFS rate of low-risk dysplasia was $90.6 \%$ (95\%CI, 0.860.96) compared with $61.7 \%$ (95\%CI, 0.44-0.80) for highrisk dysplasia. The Kaplan-Meier curve also depicts another high incidences of malignant events for patients with dysplasia occured during the 8-10 years of followup. In addition, OL located at tongue had higher malignant incidence than those found at other sites, particularly after about 10 years of follow-up (Log-rank test, $\mathrm{P}=0.047$; Figure 1B).

\section{Cox regression analysis of risk factors for $\mathrm{OL}$ malignant transformation}

An analysis of risk factors of the transformation of OL into cancer was performed by the cox proportional hazards model (Table 3 ). In the cox regression analysis, age, gender, lesion site, diet habit, smoking and ethanol intake were not found to be significantly associated with
Table 3 Cox regression analysis of risk factors for oral leukoplakia transformation

\begin{tabular}{|c|c|c|}
\hline Characteristic & Hazard Ratio $(95 \% \mathrm{Cl})$ & P-value \\
\hline \multicolumn{3}{|l|}{ Age, y } \\
\hline$<60$ & 1.00 & \\
\hline$>=60$ & $1.87(0.92-3.80)$ & 0.086 \\
\hline \multicolumn{3}{|l|}{ Gender } \\
\hline Female & 1.00 & \\
\hline Male & $0.56(0.29-1.08)$ & 0.084 \\
\hline \multicolumn{3}{|l|}{ Site } \\
\hline Other sites & 1.00 & \\
\hline Tongue & $1.97(0.99-3.93)$ & 0.053 \\
\hline \multicolumn{3}{|l|}{ Diet habit } \\
\hline Bland & 1.00 & \\
\hline Spicy & $0.41(0.10-1.70)$ & 0.217 \\
\hline \multicolumn{3}{|l|}{ Smoking } \\
\hline Never & 1.00 & \\
\hline Past and present & $0.60(0.26-1.36)$ & 0.222 \\
\hline \multicolumn{3}{|l|}{ Ethanol intake } \\
\hline Never & 1.00 & \\
\hline Past and present & $1.19(0.42-3.37)$ & 0.075 \\
\hline \multicolumn{3}{|l|}{ Epithelial dysplasia } \\
\hline Low-risk & 1.00 & \\
\hline High-risk & $4.57(2.36-8.84)$ & $<0.001$ \\
\hline
\end{tabular}

the malignant development. The risk of malignant transformation of OL located at tongue may be higher than at other sites ( $\mathrm{HR}=1.97,95 \% \mathrm{CI}, 0.99-3.93$; $\mathrm{P}=0.053)$. Importantly, the degree of dysplasia was an independent risk factor associated with malignant transformation. The high-risk dysplastic lesions were associated with 4.57-fold (95\% CI, 2.36-8.84; P < 0.001) increased the risk of malignant transformation, when compared to the low-risk dysplastic lesions.

\section{Discussion}

In the present study, we evaluated the malignant transformation rate of Chinese patients with OL, and identified the risk factors of malignant transformation during a relatively long follow-up period. Of the 218 cases, 39 (17.9\%) patients developed invasive cancer, with a mean malignant transformation period of 5.2 years. Dysplasia was an independent risk factor for OL malignant transformation, but age, gender, site, diet habit, smoking and ethanol intake were not risk factors (Table 3).

In our series, according to the WHO criteria, we considered the time elapsed from the initial diagnosis of OL to the development of cancer. In this context, we excluded patients with diagnosis of OL concomitant OSCC at the first visit or patients with a followed-up period of less than 12 months after the initial diagnosis of OL. Our recorded annual malignant rate of $3.38 \%$ is higher than the rate documented in the literature 
(0.69\%-2.03\%) [9-11]. Herein, various treatments on the OL patients were not considered because few prevention studies have shown effectiveness in preventing the transformation of OL to cancer [18].

Although it is a well-known fact that the histological classification of OL lesions is imperfect, which may involve subjectivity, we cannot do without it to date [12]. Notwithstanding it had been elucidated that oral lesions with epithelial dysplasia more often develop into cancer than those with hyperplasia in previous findings $[11,14,19,20]$, few studies have examined the risk of malignant development in different grades of dysplastic OL. In an American population, moderate or severe dysplastic OL was associated with 2.30-fold increased risk of malignant transformation, compared with mild dysplasia or hyperplasia [21]. In a Dutch study [22], OL diagnosed with moderate or severe epithelial dysplasia had a significantly higher risk of malignant development than leukoplakia with lower dysplasia grades $(\mathrm{P}<0.01)$. These findings were similar to ours. The degree of dysplasia was associated with OL malignant transformation (Table 3).

According to the new binary grading system proposed by WHO, we found the high-risk dysplastic OL was associated with a 4.57 -fold $(\mathrm{P}<0.001)$ increased risk of malignant transformation, when compared to low-risk dysplasia by Cox regression. Consistent with this result, patients with high-risk dysplastic OL had significantly higher oral cancer incidence than low-risk dysplasia, particularly during the first 2-3 years of follow-up by Kaplan-Meier curve $(\mathrm{P}<0.001$; Figue $1 \mathrm{~A})$. Similar findings were reported by Ho et al and Silverman et al $[14,16]$. It is suggested that rigorous follow-up in the first 2-3 years for patients with diagnosis of dysplastic OL may be important to detect early malignant events.

We observed the average age at diagnosis of OL is 52.7 years, while other study populations had an average age closer to 60 years $[16,20]$. The peak incidence of OL was in the fifth decade of life in our study, earlier than the sixth decade in other reports $[20,23]$. Gender predilection is not of existence in our area, but significant gender differences (ratio $\mathrm{M}: \mathrm{F}=10.6: 1$ ) were found in Taiwan, China [24]. The predominant sites of lesions are the tongue and buccal mucosa, and few lesions were located on the floor of mouth, whereas the tongue and floor of mouth were reported as the most common sites in Western countries $[6,16,20]$. These were probably due to the ethnic population and geographic difference in our cohorts compared to previous reports. Nevertheless, these factors were not related to malignant transformation of OL in our series. Moreover, It may be generally accepted that smoking and ethanol intake play significant roles in the development of OL, but the roles of those in the malignant transformation of OL is conflicting and yet unclear. The studies by Silverman et al [16] and Schepman et al [20] demonstrated an increased risk of malignant transformation in the non-smoking cohort, while the study by Ho et al [14] and our present study found smoking was not a significant factor in transformation risk. Ethanol intake was also not a risk factor for malignant transformation of OL $[14,15]$. Further prospective cohort studies are needed to investigate the roles of lifestyle habits in the malignant process of OL.

\section{Conclusions}

In summary, we evaluated the usefulness of the new binary system of grading dysplasia proposed by WHO in prediction of OL malignant transformation risk. Highrisk dysplasia was a significant indicator for OL malignant transformation. It is thus import to detect early malignant events of OL with the diagnosis of high-risk dysplasia in rigorous followed-up in the first 2-3 years.

\section{Acknowledgements}

We thank Dr. Jiang Li (Department of Oral Pathology, Ninth People's Hospital, Shanghai Jiao Tong University School of Medicine, Shanghai, China) for technical support. This study was supported by grants from Shanghai Municipal Education Commission (JDY-07061); Science and Technology Commission of Shanghai (08DZ2271100, 10DZ1974200); Shanghai Leading Academic Discipline Project (S30206); and State Administration of Traditional Chinese Medicine of China (09J1X1L420B227).

\section{Authors' contributions}

WL analyzed data and drafted the manuscript. YFW and PS collected and assembled data. HWZ participated in conception and design of the study. GYT and ZTZ coordinated and conceived the study. All authors read and approved the final manuscript.

\section{Competing interests}

The authors declare that they have no competing interests.

Received: 7 June 2010 Accepted: 16 December 2010

Published: 16 December 2010

\section{References}

1. Parkin DM, Bray F, Ferlay J, Pisani P: Global cancer statistics, 2002. CA Cancer J Clin 2005, 55:74-108.

2. Warnakulasuriya S: Global epidemiology of oral and oropharyngeal cancer. Oral oncol 2009, 45:309-316.

3. Warnakulasuriya S, Johnson NW, van der Waal I: Nomenclature and classification of potentially malignant disorders of the oral mucosa. $J$ Oral Pathol Med 2007, 36:575-580.

4. van der Waal I: Potentially malignant disorders of the oral and oropharyngeal mucosa; present concepts of management. Oral Oncol 2010, 46:423-425.

5. Scheifele C, Reichart PA: Oral leukoplakia in manifest squamous epithelial carcinoma. A clinical prospective study of 101 patients. Mund Kiefer Gesichtschir 1998, 2:326-330.

6. Haya-Fernandez MC, Bagan JV, Murillo-Cortes J, Poveda-Roda R, Calabuig C: The prevalence of oral leukoplakia in 138 patients with oral squamous cell carcinoma. Oral Dis 2004, 10:346-348.

7. Hogewind WF, van der Waal I, van der Kwast WA, Snow GB: The association of white lesions with oral squamous cell carcinoma. A retrospective study of 212 patients. Int J Oral Maxillofac Surg 1989, 18:163-164. 
8. Schepman K, van der Meij E, Smeele L, van der Waal I: Concomitant leukoplakia in patients with oral squamous cell carcinoma. Oral Dis 1999, 5:206-209.

9. Petti S: Pooled estimate of world leukoplakia prevalence: a systematic review. Oral Oncol 2003, 39:770-780.

10. Napier SS, Speight PM: Natural history of potentially malignant oral lesions and conditions: an overview of the literature. J Oral Pathol Med 2008, 37:1-10.

11. Reibel J: Prognosis of oral pre-malignant lesions: significance of clinical, histopathological, and molecular biological characteristics. Crit Rev Oral Biol Med 2003, 14:47-62.

12. Warnakulasuriya S, Reibel J, Bouquot J, Dabelsteen E: Oral epithelial dysplasia classification systems: predictive value, utility, weaknesses and scope for improvement. J Oral Pathol Med 2008, 37:127-133.

13. Kujan O, Oliver RJ, Khattab A, Roberts SA, Thakker N, Sloan P: Evaluation of a new binary system of grading oral epithelial dysplasia for prediction of malignant transformation. Oral Oncol 2006, 42:987-993.

14. Ho PS, Chen PL, Warnakulasuriya S, Shieh TY, Chen YK, Huang IY: Malignant transformation of oral potentially malignant disorders in males: a retrospective cohort study. BMC Cancer 2009, 9:260.

15. Shiu MN, Chen TH, Chang SH, Hahn LJ: Risk factors for leukoplakia and malignant transformation to oral carcinoma: a leukoplakia cohort in Taiwan. Br J Cancer 2000, 82:1871-1874.

16. Silverman S Jr, Gorsky M, Lozada F: Oral leukoplakia and malignant transformation. A follow-up study of 257 patients. Cancer 1984 53:563-568.

17. World Health Organization: World Health Organization international histological classification of tumours. In Histological typing of cancer and precancer of the oral mucosa. Edited by: Pindborg JJ, Reichart PA, Smith CJ, Van der Waal I. Berlin: Springer; 1997:21-23.

18. Lodi GSA, Bez C, Demarosi F, Carrassi A: Interventions for treating oral leukoplakia. Cochrane Databases Syst Rev 2006, CD001829.

19. Hsue SS, Wang WC, Chen CH, Lin CC, Chen YK, Lin LM: Malignant transformation in 1458 patients with potentially malignant oral mucosal disorders: a follow-up study based in a Taiwanese hospital. $J$ Oral Pathol Med 2007, 36:25-29.

20. Schepman KP, van der Meij EH, Smeele LE, van der Waal I: Malignant transformation of oral leukoplakia: a follow-up study of a hospital-based population of 166 patients with oral leukoplakia from The Netherlands. Oral Oncol 1998, 34:270-275.

21. Lee JJ, Hong WK, Hittelman WN, Mao L, Lotan R, Shin DM, Benner SE, Xu XC, Lee JS, Papadimitrakopoulou VM, Geyer C, Perez C, Martin JW, ElNaggar AK, Lippman SM: Predicting cancer development in oral leukoplakia: ten years of translational research. Clin Cancer Res 2000, 6:1702-1710.

22. Cowan CG, Gregg TA, Napier SS, McKenna SM, Kee F: Potentially malignant oral lesions in northern Ireland: a 20-year population-based perspective of malignant transformation. Oral Dis 2001, 7:18-24.

23. Banoczy J, Sugar L: Longitudinal studies in oral leukoplakias. J Oral Pathol 1972, 1:265-272

24. Lee JJ, Hung HC, Cheng SJ, Chen YJ, Chiang CP, Liu BY, Jeng JH, Chang HH, Kuo YS, Lan WH, Kok SH: Carcinoma and dysplasia in oral leukoplakias in Taiwan: prevalence and risk factors. Oral Surg Oral Med Oral Pathol Oral Radiol Endod 2006, 101:472-480.

\section{Pre-publication history}

The pre-publication history for this paper can be accessed here: http://www.biomedcentral.com/1471-2407/10/685/prepub

\section{Submit your next manuscript to BioMed Central and take full advantage of:}

- Convenient online submission

- Thorough peer review

- No space constraints or color figure charges

- Immediate publication on acceptance

- Inclusion in PubMed, CAS, Scopus and Google Scholar

- Research which is freely available for redistribution

Submit your manuscript at www.biomedcentral.com/submit
C Biomed Central 